\title{
Kolb's Learning Style Inventory 4.0 and its association with traditional and problem based learning teaching methodologies in medical students
}

\author{
Muhammad Zafar Iqbal Hydrie', Syed Muhammad Zulfiqar Hyder Naqvi², \\ Shams Nadeem Alam ${ }^{3}$, Syed Imtiaz Ahmed Jafry ${ }^{4}$
}

\begin{abstract}
Objectives: To assess learning styles and the association of various teaching methodologies of medical students.

Methods: A cross-sectional study was carried out amongst 523 medical students of Baqai Medical College, Baqai Medical University, Karachi, from July 2019 to October 2019. All students from first to final year, who attended the undergraduate MBBS program were included. The study instrument was a questionnaire containing students' demographic details, David Kolb's Learning Style Inventory 4.0 and traditional and PBL teaching methodologies were asked. The association of various learning styles and preferred teaching methodologies with year of study was also assessed by using Pearson's chi-square test.

Results: Out of 523 students, 518 returned the completed questionnaire. A majority of the students had either imagining or experiencing learning style. No change in learning style was observed between years of study. A significant association between the teaching methodologies and year of study was found in the imagining $(\mathrm{p}=0.033)$ and experiencing $(\mathrm{p}=0.044)$ learning style groups.

Conclusion: Students from different years of study at medical school did not have significantly different learning styles though the student's preferences to teaching methodologies seem to change over time in the respective learning style groups. Longitudinal studies are necessary to identify the factors influencing such change and explore the association between learning styles over time on teaching methodologies in medical education.
\end{abstract}

KEYWORDS: Academic success, Problem-Based Learning, Students, medical, Teaching methods.

How to cite this:

doi: https://doi.org/10.12669/pjms.37.1.2275

Hydrie MZI, Naqvi SMZH, Alam SN, Jafry SIA. Kolb's Learning Style Inventory 4.0 and its association with traditional and problem based learning teaching methodologies in medical students. Pak J Med Sci. 2021;37(1):146-150. doi: https://doi.org/10.12669/pjms.37.1.2275

This is an Open Access article distributed under the terms of the Creative Commons Attribution License (http://creativecommons.org/licenses/by/3.0), which permits unrestricted use, distribution, and reproduction in any medium, provided the original work is properly cited.

Correspondence:

Dr. Muhammad Zafar lqbal Hydrie, MBBS, MPhil, PhD, Postdoc Director MPH Program,

Baqai Institute of Health Sciences,

Baqai Medical University,

51-Deh Tor, Super Highway,

Gadap Road, Karachi, Pakistan.

Present Address: Professor, School of Public Health, Dow University of Health Sciences,

Ojha Campus, Karachi.

Email: zafarhydrie@gmail.com

* Received for Publication:

* $1^{\text {st }}$ Revision Received:

* $2^{\text {nd }}$ Revision Received:

* Final Revision Accepted:
January 27, 2020

May 4, 2020

September 22, 2020

October 15, 2020

\section{INTRODUCTION}

Kolb's (1984) experiential learning cycle remains one of the most widely influential and cited model of experiential learning theory with emphasis on specific place and time. ${ }^{1}$ Pipitone and Raghavan highlighted the importance of social interactions, engagement with local community and intentional cultural narrative activities in explaining the learning experience. ${ }^{2}$ Previous research using Kolb's Learning Style Inventory (KLSI) version 3.1 which identified four learning styles - Diverging, Assimilating, Converging, and Accommodating and showed that learning styles are influenced 
by culture, personality type, educational specialization, career choice, and current job role and tasks. ${ }^{1,3}$ Every learning style has got its own suitable instructional strategies and studies have shown a link between the two. ${ }^{4}$

Over the years many researchers observed that the four Kolb's learning style types had a number of borderline cases which caused confusion due to overlapping of the learning styles. These original four learning styles have recently been refined into a nine style typology that better defines the unique patterns of individual learning styles and helps reduce the confusion introduced by borderline cases in the old 4 style typology., The new nine styles defined in KLSI version 4.0 are Initiating, Experiencing, Imagining, Reflecting, Analyzing, Thinking, Deciding, Acting and Balancing. ${ }^{3}$

Learning is an exercise which demands students to act pragmatically to find solutions, through an inquiry process and clear understanding of their purposeful roles and responsibilities. ${ }^{6}$ Thus learning can be problem-based or project-based process utilizing learning methodologies such as terms associated with experiential learning which include inquiry-based learning, student-directed learning, active learning, problem-based learning, service learning, and project-based learning etc. ${ }^{7}$ There is an emphasis on learner's choice empowering them to make decisions and giving autonomy. ${ }^{8}$ Learning styles and instructional strategies in a society could be affected by many variables and understanding these helps in selecting the instructional strategies best suited to learners in the society. ${ }^{9}$ Thus the educator or teacher plays a very important role in facilitating the process, such as assisting learners to remain open to trying novel solutions to problems, encouraging tenacious attitudes, and promoting the effectiveness of communication skills. ${ }^{10}$ The learning process is often progressively difficult and educators need to gradually increase the difficulty of the intellectual, social, emotional, and/or physical challenge as the academic process proceeds ahead as seen with increasing years of study. ${ }^{11}$

Knowing the distribution of learning styles amongst medical students is therefore necessary to define which teaching methodologies will be most suited to these students. Some of the teaching methodologies such as interactive lectures, small group discussions and self-study were found to be associated with specific learning styles as reported by Costa et al. in their study. ${ }^{12}$ Similar observations were reported locally by Mukhtar et al. which found that the students preferred interactive lectures. ${ }^{13}$
In the given context, the aim of this study was to identify the various learning styles of undergraduate medical students by using the newly defined KLSI 4.0 and to determine their association with preferred teaching methodologies.

\section{METHODS}

A cross-sectional study was carried out among the medical sciences students of Baqai Medical University, Karachi, Pakistan, from July 2019 to October 2019. Ethical approval (Ref: No: FHM 2752019, Dated July 2, 2019) for the study was taken from Baqai Institute of Health Sciences.

Taking the percentage frequency of the study outcome as $50 \%$ for the most liberal estimate, with $95 \%$ confidence level and 5\% precision, the minimum required sample size was calculated to be 385 participants. A total of 523 students belonging to medical, dental, pharmacy and physiotherapy institutes of Baqai Medical University were approached using convenience sampling technique. The filling of the questionnaire by the students was considered as their consent for participation in the study. Students belonging to all educational years, i.e. from first to final year were included in the study, but since BDS and DPT only have four year course durations, and many of the final year medical students were busy in their clinical postings and could not be easily reached in the university campus, the proportion of fifth year students in the final sample was quite low.

An anonymous study questionnaire including KLSI versions 3.1 was administered to 523 undergraduates first to final year students present on the campus. The independent variables of the study were gender, year of study, and preferred teaching methodologies while learning styles were the dependent variable of the study.

The Kolbs Learning Style Inventory (KLSI) 4.0 was used to assess learning styles, it has 20 items in this format -12 that are similar to the items in the KLSI 3.1, which has been previously well validated in medical students, and eight additional items that are about learning in different contexts. ${ }^{3}$ The second part of the questionnaire was to identify their preferences for teaching methodologies which were broadly divided into traditional and problem based learning (PBL).

The data were analyzed using Statistical Package for Social Sciences SPSS (version 23.0). Descriptive analysis was performed by calculating mean and standard deviation for age and frequency and percentages for gender, learning styles, and 
teaching methodologies. Inferential analysis was performed using chi-square test while the significance level was set at 0.05 .

\section{RESULTS}

A total of 518 students completed the forms that were included in the final analysis with a response rate of $99.0 \%$. The mean age of the medical students was $21.5 \pm 1.69$ years while 307 $(59.3 \%)$ of them were females. Using David Kolb's LSI 4.0 nine style typology, it was found that 271 $(52.3 \%)$ of the medical students had Imagining, 181 (34.9\%) had Experiencing, 35 (6.8\%) had Reflecting while 25 (4.8\%) had Balancing learning style. These four learning styles out of the nine style typology accounted for $98.8 \%$ of the learning styles in this study. Moreover, $3(0.6 \%)$ students had Initiating, $2(0.4 \%)$ had Thinking while 1 $(0.2 \%)$ had Acting learning style, accounting for a total of $1.2 \%$ of the learning styles. Deciding and Analyzing learning styles were not found in any medical student in this study (Table-I).

A majority $(n=452,87.2 \%)$ of the students had Imagining or Experiencing learning styles in this study. Comparing the Kolbs 4.0 with Kolbs 3.1 learning styles we observed that of the total students with Imagining learning style $(n=271)$, a majority were Divergers $(n=205,75.6 \%)$ while the remaining were Assimilators $(n=66,24.4 \%)$. The Experiencing learning style $(\mathrm{n}=181,34.9 \%)$ included all four learning styles of Kolb`s learning style 3.1 in the order of Accommodators $(n=83$, $45.9 \%)$, Divergers $(n=63,34.8 \%)$, Convergers $(n=25,13.8 \%)$ and lastly Assimilators $(n=10$, $5.5 \%)$. It was observed that the distribution of students in the learning style groups did not change significantly with their year of study. The students in our study group predominantly adopted the Imagining and Experiencing learning styles in all years with $79.7 \%(\mathrm{n}=55)$ in first year, $81.4 \%(n=70)$ in second year, $90.7 \%(n=156)$ in third year, $88.8 \%(n=150)$ in fourth year and $95.5 \%$ $(n=21)$ in fifth year.
Table-I: Students' Kolb's LSI 4.0

Nine Learning Styles $\left(\mathrm{n}=518^{*}\right)$.

\begin{tabular}{lc}
\hline Learning Style & Count $(\%)$ \\
\hline Imagining & $271(52.3)$ \\
Experiencing & $181(34.9)$ \\
Reflecting & $35(6.8)$ \\
Balancing & $25(4.8)$ \\
Initiating & $3(0.6)$ \\
Thinking & $2(0.4)$ \\
Acting & $1(0.2)$ \\
\hline
\end{tabular}

* There were no students in the Deciding and Analyzing categories.

The teaching methods were grouped mostly as hybrid (both traditional and PBL methods) while traditional and PBL were also identified separately by the university students. Many students did not specify any teaching methods and they were grouped together as nonspecific to show no preference to any teaching method. The study results showed a significant association between teaching methodologies and year of study $(p=0.006)$ with most first, second, third and final year students preferring hybrid teaching method while most fourth year students preferring non-specific teaching method. Table-II

In this study, students having learning styles according to KLSI 4.0 were also seen for association with teaching methodology as year of study changes. It was observed that those with imagining $(n=271)$ and experiencing $(n=181)$ learning styles had significant association with year of study ( $p=0.033$ and $p=0.044$ respectively). The other teaching methodologies were not found to have any association with year of study, probably due to small sample sizes in their respective categories. Table-III.

\section{DISCUSSION}

Social scientists acknowledge the increasing role of medical education in understanding students' learning styles and their role in achieving academic success. ${ }^{14}$ To improve academic success in students and increase their motivation to learn,

Table-II: Preferred teaching methodologies according to years of study $(n=518)$.

\begin{tabular}{lccccc}
\hline Teaching Methods & 1st Year $(n=71)$ & 2nd Year $(n=88)$ & 3rd Year $(n=173)$ & 4th Year $(n=169)$ & 5th Year $(n=22)$ \\
\hline & Frequency $(\%)$ & Frequency $(\%)$ & Frequency $(\%)$ & Frequency $(\%)$ & Frequency $(\%)$ \\
\hline Hybrid & $32(45.1)$ & $33(37.5)$ & $57(32.9)$ & $52(30.8)$ & $13(59.1)$ \\
Traditional & $7(9.9)$ & $10(11.4)$ & $16(9.2)$ & $18(10.7)$ & $1(4.5)$ \\
Problem based Learning & $16(22.5)$ & $17(19.3)$ & $48(27.7)$ & $22(13.0)$ & $3(13.6)$ \\
Non-Specific & $16(22.5)$ & $28(31.8)$ & $52(30.1)$ & $77(45.6)$ & $5(22.7)$ \\
$p$ & & & 0.004 & & \\
\hline
\end{tabular}


Table-III: Kolb's 4.0 learning styles with teaching methods and year of study $(n=518)$.

\begin{tabular}{|c|c|c|c|c|c|c|}
\hline \multirow[t]{2}{*}{ Learning Style } & 1st Year $(n=69)$ & 2nd Year $(n=86)$ & $3 r d$ Year $(n=172)$ & 4th Year $(n=169)$ & 5th Year $(n=22)$ & \multirow[t]{2}{*}{$p$} \\
\hline & Frequency $(\%)$ & Frequency $(\%)$ & Frequency $(\%)$ & Frequency $(\%)$ & Frequency $(\%)$ & \\
\hline Imagining $(n=271)$ & $34(49.3 \%)$ & $42(48.8 \%)$ & $85(49.4 \%)$ & $99(58.6 \%)$ & $11(50.0 \%)$ & 0.033 \\
\hline Hybrid teaching $(n=96)$ & $16(16.7 \%)$ & $15(15.6 \%)$ & $25(26 \%)$ & $32(33.3 \%)$ & $8(8.3 \%)$ & \\
\hline PBL teaching $(n=58)$ & $8(13.8 \%)$ & $5(8.6 \%)$ & $27(46.6 \%)$ & $18(31 \%)$ & Nil & \\
\hline Traditional $(\mathrm{n}=24)$ & $3(12.5 \%)$ & $4(16.7 \%)$ & $4(16.7 \%)$ & $12(50 \%)$ & $1(4.2 \%)$ & \\
\hline Non-specific $(\mathrm{n}=93)$ & $7(7.5 \%)$ & $18(19.4 \%)$ & $29(31.2 \%)$ & $37(39.8 \%)$ & $2(2.2 \%)$ & \\
\hline Experiencing $(\mathrm{n}=181)$ & $21(30.4 \%)$ & $28(32.6 \%)$ & $71(41.3 \%)$ & $51(30.2 \%)$ & $10(45.5 \%)$ & 0.044 \\
\hline Hybrid teaching $(n=68)$ & $9(13.2 \%)$ & $9(13.2 \%)$ & $29(42.6 \%)$ & $16(23.5 \%)$ & $5(7.4 \%)$ & \\
\hline PBL teaching $(n=31)$ & $4(12.9 \%)$ & $6(19.4 \%)$ & $15(48.4 \%)$ & $4(12.9 \%)$ & $2(6.5 \%)$ & \\
\hline Traditional $(n=23)$ & $3(13 \%)$ & $6(26.1 \%)$ & $11(47.8 \%)$ & $3(13 \%)$ & Nil & \\
\hline Non-specific $(\mathrm{n}=59)$ & $5(8.5 \%)$ & $7(11.9 \%)$ & $16(27.1 \%)$ & $28(47.5 \%)$ & $3(5.1 \%)$ & \\
\hline Reflecting $(n=35)$ & $8(11.6 \%)$ & $9(10.5 \%)$ & $6(3.5 \%)$ & $12(7.1 \%)$ & Nil & 0.300 \\
\hline Hybrid teaching $(\mathrm{n}=11)$ & $4(36.4 \%)$ & $3(27.3 \%)$ & $1(9.1 \%)$ & $3(27.3 \%)$ & Nil & \\
\hline PBL teaching $(n=7)$ & $2(28.6 \%)$ & $3(42.9 \%)$ & $2(28.6 \%)$ & Nil & Nil & \\
\hline Traditional $(\mathrm{n}=2)$ & Nil & Nil & Nil & $2(100 \%)$ & Nil & \\
\hline Non-specific $(n=15)$ & $2(13.3 \%)$ & $3(20 \%)$ & $3(20 \%)$ & $7(46.7 \%)$ & Nil & \\
\hline Balancing $(n=25)$ & $5(7.2 \%)$ & $4(4.7 \%)$ & $9(5.2 \%)$ & $6(3.6 \%)$ & $1(4.5 \%)$ & 0.156 \\
\hline Hybrid teaching $(n=6)$ & $1(16.7 \%)$ & $3(50 \%)$ & $2(33.3 \%)$ & Nil & Nil & \\
\hline PBL teaching $(n=7)$ & $2(28.6 \%)$ & $1(14.3 \%)$ & $3(42.9 \%)$ & Nil & $1(14.3 \%)$ & \\
\hline Traditional $(n=3)$ & $1(33.3 \%)$ & Nil & $1(33.3 \%)$ & $1(33.3 \%)$ & Nil & \\
\hline Non-specific $(\mathrm{n}=9)$ & $1(11.1 \%)$ & Nil & $3(33.3 \%)$ & $5(55.6 \%)$ & Nil & \\
\hline
\end{tabular}

it is important to identify their learning styles and to regulate the educational programs accordingly. The goals of medical schools can be better achieved by encouraging students to identify their own learning styles and realize their strong and weak points in learning, instructing them about how to improve their weaknsses, and raising awareness of the students' learning styles among tutors and teachers. ${ }^{15,16}$ In our study, we defined learning styles using the revised David Kolb's 4.0 nine style typology to evaluate the learning styles among the students of a medical university. More than half of the students were found to have Imagining learning style which according to the previous Kolb's 3.1 version included Divergers and Assimilators. As we could not find any study using the new KLSI 4.0 so we compared studies which used KLSI 3.1 and found that most studies done in Pakistan and surrounding countries such as Turkey and Saudi Arabia have reported Divergers as predominant style, as also seen in our study using KLSI 4.0, which is the major of the two groups included in Imagining learning style in the new nine style typology. ${ }^{17,18}$ According to KLSI 3.1, the other group in the Imagining KLSI 4.0 is Assimilators and a previous study has found medical students to predominantly have assimilating learning style. ${ }^{14}$ It was determined in another study using KLSI 3.1 that the greatest change between the learning styles took place in the group of Divergers where a great majority of these students shifted to the assimilating learning styles over time. ${ }^{19,20}$ Divergers and Assimilators are the two learning styles according to KLSI 3.1 present in the new 4.0 version of Imagining learning style we could not detect any change if students shifted from Diverger to Assimilator learning style or vice versa in the new typology. The next predominant learning style in our study according to KLSI 4.0 was Experiencing learning style $(n=181,34.9 \%)$ and included all the learning styles of KLSI 3.1 in the order of mostly accommodators followed by Divergers, Convergers and a few Assimilators.

In our study students were also asked which teaching methodology was preferred by them. The results in a study done using KLSI 3.1 by Gurpinar et al., aimed at determining which educational methods are commonly preferred by medical students and increase their success the majority showed that assimilators were more successful in the courses based on traditional education while Convergers were more successful in the courses based on PBL. ${ }^{18}$ In our study, the overall major preference was for a combined teaching methodology since medical students adopt a variety of teaching methods to boost their learning potential depending on the course requirements and nature of study. The result of the present study also showed that medical students had a change in preference to the teaching methods over the year 
of study. Nearly $90 \%$ of the medical students in this study had either Imagining or Experiencing learning styles and both learning styles were found to be significantly associated with the year of study.

Limitations of the study: As this was a crosssectional study, we could only compare the students in different years of study and not follow them prospectively. A longitudinal cohort study is needed to be planned to continue to follow and observe the same students over an extended period of time. Results from such a cohort will help to determine whether medical education influences learning styles and vice versa, which incites their change as suggested by our study.

\section{CONCLUSION}

Different teaching methods at the medical college did not significantly influence the students' learning styles, however students preferred teaching methods and individual learning styles were affected by their year of study. Studies planned for a longer duration following students as they progress through their pre-clinical and clinical careers are needed to further explore the factors which may influence medical students preferred teaching methods and learning strategies.

\section{Source of Funding: None.}

\section{Conflicts of Interest: None.}

\section{REFERENCES}

1. Kolb DA. Experiential learning: Experience as the source of learning and development. FT press; 2014 Dec 17.

2. Pipitone JM, Raghavan C. Socio-spatial analysis of study abroad students' experiences in/of place in Morocco. J Exp Educ. 2017;40(3):264-278. doi: 10.1177/1053825917709823

3. Kolb AY. The Kolb Learning Style Inventory 4.0: A comprehensive guide to the theory, psychometrics, research on validity and educational applications. Philadelphia, PA: Hay Group. 2013. Available online on $26^{\text {th }}$ February 2020. Url: https://learningfromexperience.com/research-library/thekolb-learning-style-inventory-4-0/

4. Newble DI, Entwistle NJ. Learning style and approaches: implications for medical education. Med Educ. 1986;20(3):162175. doi: 10.1186/1472-6920-13-42

5. Kolb AY, Kolb DA. Learning styles and learning spaces: Enhancing experiential learning in higher education. Acad Manag Learn Educ. 2005;4(2):193-212.

6. Bialka CS, Havlik SA. Partners in learning: Exploring two transformative university and high school servicelearning partnerships. J Exp Educ. 2016;39(3):220-237. doi: 10.1177/1053825916640539

7. Blair DJ. Experiential learning for teacher professional development at historic sites. J Exp Educ. 2016;39(2):130-144 doi: $10.1177 / 1053825916629164$

8. Barron D, Khosa D, Jones-Bitton A. Experiential learning in primary care: Impact on veterinary students communication confidence. J Exp Educ. 2017;40(4):349-365. doi: $10.1177 / 1053825917710038$
9. Mustafa AG, Allouh MZ, Mustafa IG, Hoja IM. Anatomy learning styles and strategies among Jordanian and Malaysian medical students: the impact of culture on learning anatomy. Surg Radiol Anat. 2013;35(5):435-441. doi: 10.1007/s00276012-1067-z

10. Valley K. Learning styles and courseware design. Assoc Learn Tech J. 1997;5:42-51.

11. Isaak J, Devine M, Gervich C, Gottschall R. Are we experienced? Reflections on the SUNY experiential learning mandate. J Exp Educ. 2018;41(1):23-38. doi: 10.1177/1053825917740377

12. Costa ML, van Rensburg L, Rushton N. Does teaching style matter? A randomised trial of group discussion versus lectures in orthopaedic undergraduate teaching. Med Educ. 2007;41(2):214-217. doi: 10.1111/j.1365-2929.2006.02677.x

13. Mukhtar F, Hashmi N, Rauf MA, Anzar A, Butt KI, Ahmed $\mathrm{M}$, et al. Teaching methodologies; what is the students' perspective? Prof Med J. 2012;19(5):597-603.

14. Sternberg RJ, Grigorenko EL, Zhang LF. Styles of learning and thinking matter in instruction and assessment. Perspect Psychol Sci. 2008;3(6):486-506. doi: 10.1111/j.1745-6924.2008.00095.x

15. Dolmans DH, Wolfhagen IH. The relationship between learning style and learning environment. Med Educ. 2004;38(8):800. doi: 10.1111/j.1365-2929.2004.01941.x

16. Rosenfeld M, Rosenfeld S. Understanding teacher responses to constructivist learning environments: Challenges and resolutions. Sci Educ. 2006;90(3):385-399. doi: 10.1002/ sce. 20140

17. Danish KF, Awan AS. A study of student's learning styles in a medical institution in Pakistan. Rawal Med J. 2008;33:239-241.

18. Gurpinar E, Alimoglu MK, Mamakli S, Aktekin M. Can learning style predict student satisfaction with different instruction methods and academic achievement in medical education? Adv Physiol Educ. 2010;34(4):192-196. doi: 10.1152/advan.00075.2010

19. Buali WH Al, Balaha MH, Muhaidab NS Al. Assessment of learning style in a sample of saudi medical students. Acta Inf Med. 2013;21(2):83-88. doi: 10.5455/aim.2013.21.83-88

20. Gurpinar E, Bati H, Tetik C. Learning styles of medical students change in relation to time. Adv Physiol Educ. 2011;35(3):307311. doi: $10.1152 /$ advan.00047.2011

\section{Authors' Contribution:}

MZIH conceived, designed and did data collection, statistical analysis \& manuscript writing.

SMZHN \& SNA did review \& editing of manuscript. SIAJ did final approval of manuscript.

MZIH, SMZHN, SNA \& SIAJ ensured accuracy and integrity of work.

Authors:

1. Dr. Muhammad Zafar lqbal Hydrie, MBBS, MPhil, PhD, Postdoc Department of Community Medicine,

Present Address: Professor, School of Public Health, Dow University of Health Sciences, Ojha Campus, Karachi.

2. Dr. Syed Muhammad Zulfiqar Hyder Naqvi, MSBE. Department of Community Medicine,

3. Dr. Shams Nadeem Alam, FRCS, MHPE. Department of Medical Education,

4. Dr. Syed Imtiaz Ahmed Jafry, MPH. Department of Community Medicine,

1-4: Baqai Medical University, Karachi, Pakistan. 